\section{Editorial}

Check for updates

\section{OPEN ACCESS}

Received: Feb 9, 2019

Accepted: Feb 21, 2019

${ }^{*}$ Correspondence:

Young Ku

Department of Periodontology, Seoul National

University School of Dentistry, 103 Daehak-ro,

Jongno-gu, Seoul 03080, Korea.

E-mail: guy@snu.ac.kr

Tel: +82-2-2072-3182

Fax: +82-2-744-0051

Copyright (c) 2019. Korean Academy of Periodontology

This is an Open Access article distributed under the terms of the Creative Commons Attribution Non-Commercial License (https://

creativecommons.org/licenses/by-nc/4.0/).

ORCID iDs

Young Ku iD

https://orcid.org/0000-0001-5682-0604

\title{
Opening a new chapter of Journal of Periodontal \& Implant Science
}

Young Ku ${ }^{\circledR}$, President of the Korean Academy of Periodontology

Department of Periodontology, Seoul National University School of Dentistry, Seoul, Korea

The Journal of Periodontal \& Implant Science (JPIS) was first launched as the Journal of the Korean Academy of Periodontology in 1971. In 2010, the journal changed its name, format, publishing type, and language policy to become more accessible and available worldwide, after which it expanded into an international journal focusing on the fields of periodontal and Implant science.

Thanks to the efforts made by the former editorial board members, JPIS is indexed/tracked/ covered by PubMed, PubMed Central, Science Citation Index Expanded (SCIE, Web of Science), Scopus, KoreaMed, Synapse, KoMCI, the Chemical Abstracts Service (CAS), Cambridge Scientific Abstracts (CSA), and Google Scholar. In 2017, the journal impact factor of JPIS reached 1.072 (5-year impact factor, 1.554) based on Web of Science.

The outgoing Editor-In-Chief and board members have certainly raised the bar for the incoming editorial members, and their work is appreciated with the utmost sincerity. The new publication team will leverage this strong foundation and continue this momentum to become a global leading journal in the field of periodontology and implantology. 